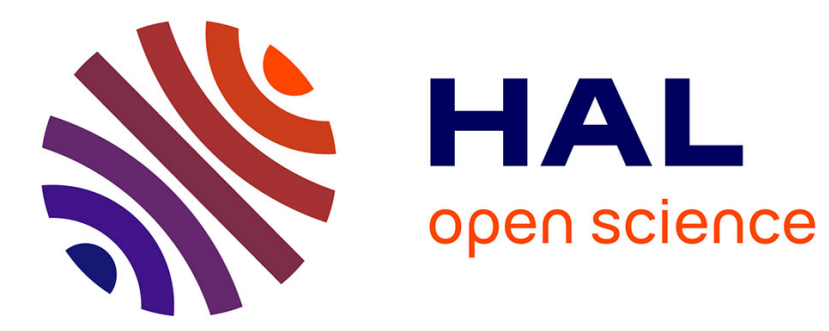

\title{
EXPERIMENTAL STUDY OF THE ULTRASONIC FIELD SCATTERED FROM AN IMMERSED ELASTIC WEDGE
}

J. Piet, M. de Billy

\section{> To cite this version:}

J. Piet, M. de Billy. EXPERIMENTAL STUDY OF THE ULTRASONIC FIELD SCATTERED FROM AN IMMERSED ELASTIC WEDGE. Journal de Physique IV Proceedings, 1992, 02 (C1), pp.C1-683-C1-686. 10.1051/jp4:19921148 . jpa-00251106

\section{HAL Id: jpa-00251106 https://hal.science/jpa-00251106}

Submitted on 1 Jan 1992

HAL is a multi-disciplinary open access archive for the deposit and dissemination of scientific research documents, whether they are published or not. The documents may come from teaching and research institutions in France or abroad, or from public or private research centers.
L'archive ouverte pluridisciplinaire HAL, est destinée au dépôt et à la diffusion de documents scientifiques de niveau recherche, publiés ou non, émanant des établissements d'enseignement et de recherche français ou étrangers, des laboratoires publics ou privés. 


\title{
EXPERIMENTAL STUDY OF THE ULTRASONIC FIELD SCATTERED FROM AN IMMERSED ELASTIC
} WEDGE

\section{J.F. PIET and M. DE BILLY}

Groupe de Physique des Solides, Universités Paris 6 et 7, Tour 23, 2 place Jussieu, F-75251 Paris cedex 05, France

\begin{abstract}
In this paper we investigate the interaction of a bounded acoustic beam incident on a $90^{\circ}$ wedge shaped sample immersed in a fluid (water).The variations of the amplitude of the signal radiated by the tip of the wedge in a plane perpendicular to the edge are recorded against the scattering angle and plotted in polar diagrams. The influence of different parameters such as the frequency and the angle of incidence on the experimental results are more specifically investigated.Some of the data are compared to optical experiments using a pulsed schlieren technique.
\end{abstract}

\section{Introduction}

In a previous paper [1] we pointed out that when a $90^{\circ}$ corner is tangentially insonified by a bounded acoustic beam,the polar diagrams showing the variations of the scattered signal by the tip of the wedge,are characterized by the presence of maximum at specific angles. The experiments were achieved on different materials at $2.5 \mathrm{MHz}$ with short pulses (five to ten oscillations).In the present work we investigate the influence of various geometrical and acoustic parameters on the variations of the amplitude of the scattered signal against the scattering angle.Quantitative results are compared with qualitative informations obtained from acousto-optic experiments.

I Experimental study showing the dependence of the angular plots versus the angle of the wedge and the angle of incidence.

To explain the origin of the surface waves which exist when the incident beam interacts with the wedge, it is important to study the influence of the angle of the wedge and of the angle of incidence (Fig.1) on the generation of these waves. 
a-The angle of incidence $(\Psi)$ varies and $\Phi=0^{\circ}$. When the angle $\Psi$ varies, the same phenomena that we noticed for $\Psi=0^{\circ}$ are observed.This is illustrated in figure 2 where are plotted the experimental data obtained for $\Psi=45^{\circ}$. with a duraluminum corner. We notice the presence of two small peaks bofore the large one due to the specular reflection.

$b$-The angle of the wedge $(\Phi)$ varies and $\Psi=0^{\circ}$.Two situations have to be distinguished.The first one considered here is obtained when one of the planes making up the corner is perpendicular to the incident beam as the angle $\Phi$ varies. Then the angular plots point out that the amplitude of the second peak (large incident angle) increases with the angle $\Phi$ in comparison with the amplitude of the first peak(low incident angle).This behavior is shown in figure 3.By investigating the complementary situation (the fixed plane is now tangential to the average direction of the beam), we notice the existence of two maxima the relative amplitudes of which changes also with the angle of the wedge as reported in figure 4.

c- The angles $\Psi$ and $\Phi$ vary simultaneously with $\Psi \equiv \Phi\lfloor 2$. Th is symmetric situation points out experimental data which are redrawn in figure 5 for $\Psi=2 \Phi=20^{\circ}$.In addition to the peaks due to the leaking waves,we observe the presence of a large extremum the origin of which has not been yet explained until now.

From these results we conclude that the amplitudes of the reemission of the different leaky surface waves are strongly dependent on $\Psi$ and $\Phi$.Particular range of values of these angles are favourable for their generation. These results should be interesting for the identification of the surfaces waves.

II Influence of the frequency on the angular plots : experimental results and discussion.

It is an important objective to verify the influence of the frequency on the experimental records.It is wellknown that the resolution increases with the frequency.The results plotted in figure 6 illustrate very clearly this property.The consequence of the beam aperture dependence with the frequency $(1 / f)$ is also illustrated in the figure 7 which represents the polar diagrams recorded for $\Psi=45^{\circ}$ with a duraluminum sample at $\mathrm{f}=0.5 \mathrm{MHz}$ (Fig.7a) and $\mathrm{f}=5 \mathrm{MHz}$ (Fig.7b).

III Optical visualisation of the acoustic field near the corner.

To visualize the acoustic field diffracted by the tip of the wedge,we used a pulsed schlieren system by using short ultrasonic pulses [2].An example of the wavefronts scattered from the elastic wedge in water is represented in figure $7 \mathrm{a}$ for a particular simple case:a tangential incidence on a right corner of a duraluminum block.In figure $7 \mathrm{~b}$ the different wavefronts are identified.This visualisation confirms the reemission under critical angles that we observed by measuring the amplitude of the field radiated by the wedge in water. 

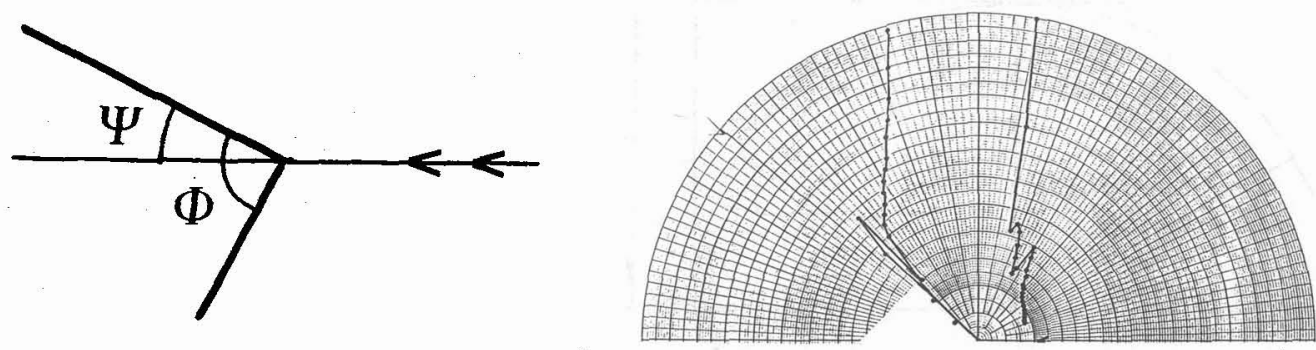

Fig.1 Definition of the geometrical angles.

Fig.2 Angular diagram obained for $\Psi=45^{\circ}$ on a quarter angle duraluminum sample.
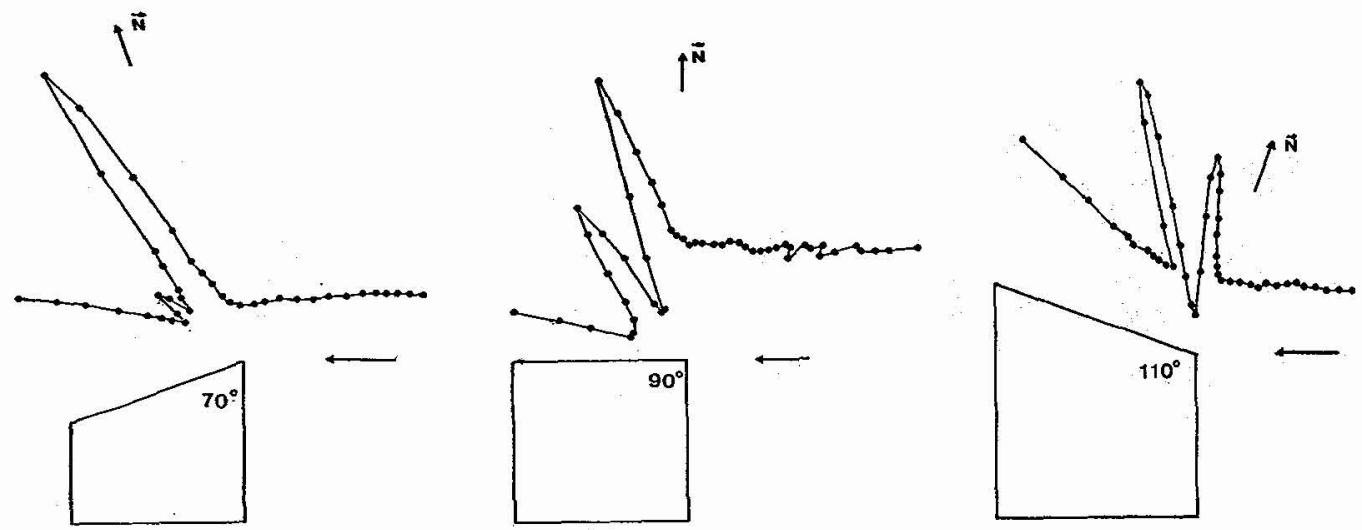

Fig.3 Comparison of the polar diagrams observed for a constant value of $\Psi\left(90^{\circ}\right)$ and different values of $\Phi\left(70^{\circ}, 90^{\circ}, 110^{\circ}\right)$.

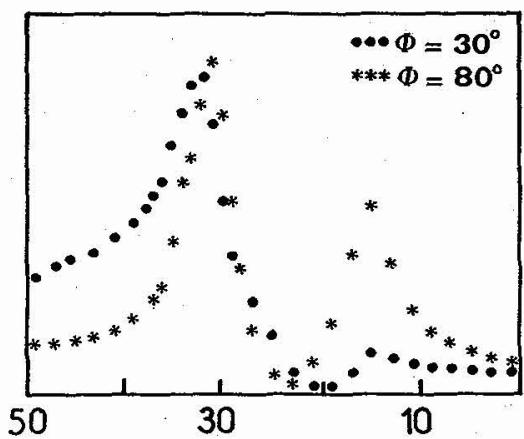

Fig.4 Linear diagrams showing the influence of the value of $\Phi$ on the relative amplitude of the two peaks for $\Psi=0^{\circ}$.

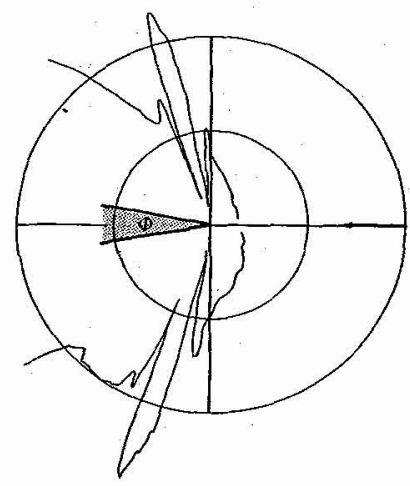

Fig.5 Polar diagram observed for $\Psi=\Phi / 2=10^{\circ}(\mathrm{F}=2.5 \mathrm{MHz})$ on a duraluminum sample. 

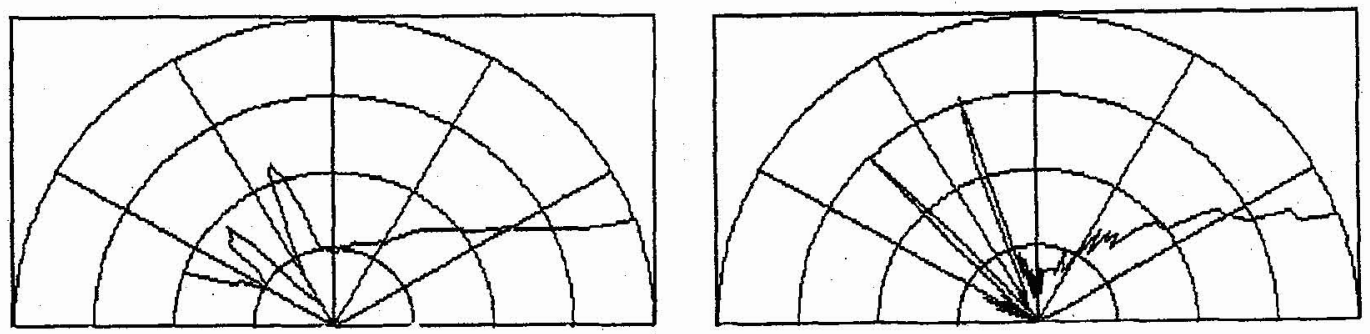

Fig.6 Polar diagrams showing the influence of the frequency
a) $\mathrm{F}=0.5 \mathrm{MHz}$
b) $\mathrm{F}=5 \mathrm{MHz}$.
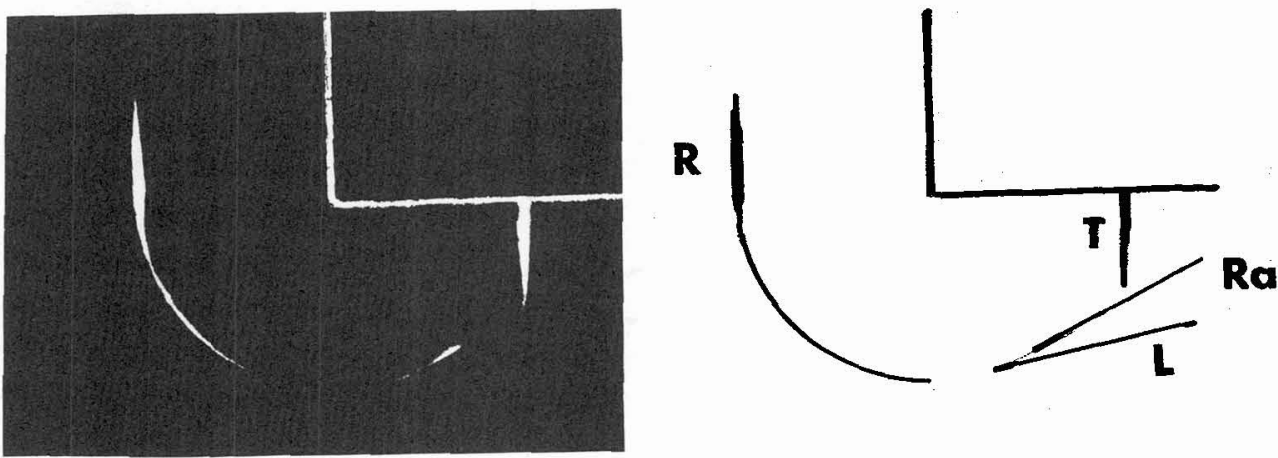

Fig.7 a) Schlieren picture showing the wavefronts diffracted by a quarter-wedge. b) Identification of the different wavefronts.

\section{Conclusion}

These results related in this paper confirm that optimal geometric situations are necessary for generating surface waves when an acoustic beam interacts with a wedge.The first one exists whatever is the orientation of the wedge in comparison with the direction of the incident beam.The second one appears only at grazing angle.These observations are qualitatively confirmed by optical measurements.

\section{Bibliography}

1- J.F.Piet and M. de Billy "Experimental study of the scattering of a compressional wave by an elastic wedge"J.Appl.Phys.69,6904$6909(1991)$.

2- J.F. Piet "Réalisation d'un système de visualisation des ultrasons par une méthode acousto-optique"Rapport interne (sept. 91). 